\title{
Electronic Study Books and learning style
}

\author{
I.P.F. De Diana and G. van der Heiden \\ University of Twente, The Netherlands
}

\begin{abstract}
Attention has been drawn to the concepts of Electronic Books and Electronic Study Books. Several publications have discussed some main ideas (paradigms) for both concepts. For the Electronic Study Book as a learning environment, it is essential to consider individual modes of learning, usually termed learning styles'. It is argued that Electronic Study Books should be adaptable in accordance with personal learning styles. Some options will be presented to link 'styles' and 'books'. One such option is a Style Initiating Module which we are currently investigating.
\end{abstract}

Keywords: Courseware; Electronic books; Electronic study books; Electronic learning environment; Learning style.

\section{Electronic Books}

In a series of articles (Barker, 1990; Barker \& Manji, 1989; Egan et al., 1989) and in a special issue of Educational \& Training Technology International (Barker, 1991) the nature and the educational potential of Electronic Books and Electronic Study Books (De Diana, 1991) have been discussed.

By combining traditional book concepts with some of the advantages of electronic media, it is presumed that the Electronic Book could become a late 20th century successor of the Paper Book.

In Barker (1990), hypermedia, reactive media, the principle of surrogation, learner control, and the composite screen are presented as paradigms for the Electronic Book. The hypermedia paradigm involves the nonlinear structuring of units of (multimedial) information. The units can be connected in several ways and thus become a network that can be travelled through ('navigated') by learners in different ways. Reactive media involve interaction between humans and computers; the dialogue can be initiated, responded to, or stopped by both partners. The principle of surrogation builds upon the capacity of the computer to simulate parts of the real world visually. Computer animation can be used to create visualisations of (small) explorable worlds. Learner control implies that the learner can control the learning process. The composite screen paradigm presumes the facility of

Correspondence: Dr. Italo De Diana, Faculty of Educational Science and Technology, University of Twente, P.O. Box 217, 7500 AE Enschede, Netherlands. $\quad$ Email: diana@edte.utwente.nl 
opening simultaneously multiple windows and displaying different streams of information through these windows.

The key distinction between the paper book and the electronic book is to be found in the additional cognitive support facilities that the electronic book could offer. Facilities, for example, to support information selection, information processing, information evaluation, and information approval or rejection. An electronic book then can be seen as an interactive 'mindtool', connected with a multimedial data base.

\section{Electronic Study Books}

Some facilities that could turn an Electronic Book into an Electronic Study Book are, according to De Diana (1991): information marking, annotation, support for group-based learning, information sequencing, and support for information distribution.

\section{Identifying scope and relevance of study material}

It is customary, though not always approved of, for readers to mark important passages in study books such as keywords, keyphrases, paragraphs or comments so that they stand out from their surrounding context. Such marking indicates high relevance and makes it more. convenient to (re-)locate relevant information. By studying a profile of marking created by someone who studied the book before, an impression can emerge about the (perceived) major topics and parts of the book. Furthermore, identifying the scope can support learning activities by focusing attention and support individualized study if marking takes place to meet the needs of specific learners.

The electronic study book can improve upon the paper book. By means of electronic marking, areas of more or less relevance can be coded by a teacher or a learner. Coding can be represented visually to a learner by highlighting (for example, selected keywords) or by the use of other information display parameters. Parameterization of marking can take place in accordance with the preferences of individual learners and thus can become individualized. Key areas can be individualized as well, by specifying the relevance of diverse parts of the information for particular learners.

\section{Adding to available study materials}

Writing comments in the margins of paper (study) books is not an unusual practice while studying, as is making footnotes and references to other materials. The concept of adding information to study materials for the purpose of enriching them is not a new concept. The electronic study book can allow both multimedia and multipersonal annotations that could be activated and deactivated selectively by the user. Annotations might consist of pointers to other study material or they could consist of a formal 
description of the knowledge contained in the study materials (Moulin \& Rousseau, 1990). Annotations of a multipersonal nature could result from allowing different persons to annotate the same materials.

\section{Communication facilities and the book}

Johnson \& Johnson (1987) have given clear indications that cooperative learning can be a very effective. Quite a lot of human learning addresses interpersonal issues, directed at topics such as cooperating with other people, acquiring management skills, and learning how to run a company. The paper book can support groups to acquire such skills, either by informing them how to acquire them or by structuring the acquisition process, as for example is the case with paper-based Business Games. Electronic mail, perhaps multimedial (Borenstein \& Thyberg, 1991), can be of prime importance for cooperation. Research and development work on information filtering and on using an information lens for group-based activities (Lai, Malone \& Yu, 1989) might assure that mailing be content specific and thus linked to specific electronic book contents.

\section{Routing the learner through the book}

Structuring the sequence of information is a well established educational approach. A paper book can offer 'internal' directions for sequencing, for instance by the way its chapters are organized. Directions for information sequencing can also be provided in a 'weak' sense, such as in instructions for reading a book contained in an introductory section. A book can be enriched from 'external' study instructions, for instance those contained in course information identifying the book's relevant content. Strong directions can be offered by routing a learner along study paths as is usual in (intelligent) tutorials.

The electronic successor can improve upon its predecessor by offering computerized support for information sequencing. A variety of options to do so already exist. We can mention computer supported learning, and especially 'tutoring', as a common way to sequencing support. Literature on tutoring often stresses record keeping of learners' sequential path behaviour with timely and appropriate feedback of study results as valuable sequencing support functions.

\section{Management of information}

Traditionally, the paper book has been the foremost distribution medium of information. Printers, publishers, booksellers, and libraries are instrumental in distributing a continuous stream of study information to potential learners. The whole system of distribution serves a logistical function, the net effect being that learners are able to acquire the necessary information.

It is not easy for an electronic book to be able to improve upon the paper book in mant respects. Improvement is possible however, at least from the 
point of view of the user. Improvement can be found in making the successor 'soft', that is, the electronic book should allow for additions and (maybe) modifications. We have been discussing possibilities for marking, annotating, filtering and sequencing which are all options to modify the original material for study purposes. As copyright issues are clearly involved, we expect electronic books to be hybrids. One part of the book will probably be hard: the original source materials as distributed by publishers; one part could be soft and could consist of additions to the hard part such as annotations.

\section{Book users and product adaptation}

As has been argued by De Diana and de Vries (1990), an increasing need is felt for adaptable educational software products that can be modified to the needs of users. In fact, both the concepts of electronic book and electronic study book offer ample options for product adaptation such as:

- relations between multimedia information units;

- changes in reactive output as a consequence of the setting of switches;

- aspects of information display;

- what, how, and in what way to learn;

- where to present what kind of information.

The wish for adaptability should not to be seen as a problem. An electronic study book is designed to grow and develop and should not be seen not as a static product. Adaptations and additions might mark important conceptual transitions in a book's life.

\section{The Electronic Study Book as a learning environment}

The Electronic Study Book has various educational functions. In the first place, the book is based upon one or more multimedia educational databases. Secondly, the book contains information about ways to relate multimedia information elements contained in the databases, either by a hypermedia approach or by study routes. Thirdly, the book offers its users a modifiable interface, allowing for the setting of switches and opening and addressing windows. In the fourth place, the book allows for information addition to databases: by marking, by annotation, by mail, and by storing distribution information.

The Electronic Study Book needs a software environment which supports these functionalities. This will be composed of software tools to support user behaviour in relationship to the book, such as 'add to content base', 'change study route', 'annotate book' and so on.

The various types of information contained in the book and the set of book functions that can be activated by means of the available tools, make up the Learning Environment. In combination they define what can be learned and how. 


\section{Learner characteristics and the learning environment}

How learning actually takes place in a learning environment depends upon the learner's individual mode or 'style' of learning. Marton and Saljö (1984) describe how one can place a learner's style on a continuum that extends from surface processing of symbols to deep analysis of the meanings that underlie the symbols. The deeper the processing of information, the better it is remembered. Although styles differ between people, three major categories can be distinguished: deep, surface, and strategic (Entwistle, 1988).

\section{Learning situations and learning environment}

Learning situations are, stated in general terms, situations in which individuals, due to events that take place, change their cognitive structures. This can be intentional or incidental. Learning situations consist of learning tasks and the context in which the tasks are executed. In general, learning styles are persistent over situations that are perceived to hold the same learning tasks.

Learning environments are part of the learning situation. They are the educational settings in which the learning process takes place.

Motives and intentions relate to a learner's conception of learning. They are influenced by aspects of the learning situation and together form an image of the new situation. This image will be matched internally with prior experience patterns: 'What kind of situation is this and what does it mean to me?' (Schmeck, 1988a). Every pattern can lead to specific perceptions of the situation. If students are instructed to prepare for an examination in a specific course, then to some extent one can predict their behaviour by asking: 'What does an examination in this course mean to you?'. In this way, it is possible to begin to understand the patterns that enter into the students' perceptions of the learning situation.

\section{Learning style and a learning style model}

Entwistle (1988) presents a model in which qualitative and quantitative research on approaches to learning are integrated. Biggs (1988) defines an approach to learning as: 'the learning processes that emerge from learners' perceptions of the academic task, as influenced by their personal characteristics'. Accordingly, we presume that an approach to learning can be conceived of as a learning style.

Entwistle distinguishes between three styles: surface, deep, and strategic. These styles are based upon learners' motivations, learners' intentions and upon related learning strategies.

Learning strategies consist of any behavioural or thought patterns that facilitate encoding in such a way that knowledge integration and retrieval are enhanced. So, in respect to learning tasks, learning styles can be conceived of as persistently used learning strategies (Schmeck, 1988a). 


\section{I.P.F. De Diana and G. van der Heiden}

Although learning strategies determine the way in which information is processed, they are not manifest. In traditional educational settings learners, among other activities, annotate, write comments or ask for pictorial information. Such visible events are the external expression of specific learning strategies. Such visible events that 'implement' a learning strategy can be termed learning tactics (Schmeck, 1988b). These kinds of tactics comprise the learner's actions upon which the computer can adapt its behaviour.

In Table 1 a simplified form of this model is shown. Learning tactics have been added to the original figure.

Table 1. Approaches to learning according to Entwistle.

\begin{tabular}{|c|c|c|c|}
\hline & surface & deep & strategic \\
\hline motivation & $\begin{array}{l}\text { to complete the course } \\
\text { fear of failure }\end{array}$ & $\begin{array}{l}\text { interested } \\
\text { vocational relevance }\end{array}$ & $\begin{array}{l}\text { to get high grades } \\
\text { competitive }\end{array}$ \\
\hline intention & $\begin{array}{l}\text { to reproduce what } \\
\text { is expected }\end{array}$ & $\begin{array}{l}\text { to reach personal } \\
\text { understanding }\end{array}$ & $\begin{array}{l}\text { to be successful with } \\
\text { whatever means needed }\end{array}$ \\
\hline strategy & rote learning & $\begin{array}{l}\text { operational learning or } \\
\text { comprehensive learning } \\
\text { or versatile learning }\end{array}$ & $\begin{array}{l}\text { operational learning or } \\
\text { comprehensive learning } \\
\text { or versatile learning }\end{array}$ \\
\hline tactios & memory directed & comprehension directed & \\
\hline
\end{tabular}

Motivation of learners

Motivation is predominantly set by people's expectations about their own abilities. Personal expectations influence the choice of activities, the degree of effort one is willing to invest, and the degree of persistence in the face of failure (Bandura, 1982). For instructional materials this implies that they must be lucid, considerate, and enjoyable (Paris, 1988) in order to be able to influence learners' motivation in a positive sense and promote effective learning.

Individuals with a surface approach to learning mostly perceive themselves as being of low competence. These learners will not invest much energy because any failure will directly be related to a lack of ability which consequently lowers self-esteem and strengthens fear of failure. Their motivations are predominantly extrinsic.

Deep learners are intrinsically as well as extrinsically motivated. Intrinsically because they are sincerely interested in the subject matter, and extrinsically because they perceive the course to be of vocational relevance.

Strategic learners are mainly concerned with reinforcing their academic self-concept through repeated demonstrations of intellectual mastery (Entwistle, 1988). 


\section{Learning strategies}

Learners who are afraid to fail will be likely to adopt a surface-oriented style. They will use memorising strategies and focus upon pieces of information in isolation; they will literally memorize these in order to be able to recall the information when taking a test.

Learners who perceive courses as a means to develop a better understanding of the world around them will adopt a deep style. They will use strategies to explore new information based upon connections to prior knowledge; they will imagine and make inferences about the new material and emphasise it in the current context.

Deep learners also make use of a concept oriented strategy if they create for themselves a (hierarchical) network in which new information is organized, categorized, and examined for flaws. In this case they make use of operation-oriented learning. An optimal learning environment will support learners to use various types of strategy which can result in versatile learning.

The last group of learners, the competitive ones, will use rote learning, or operation learning, or comprehension learning, or combinations depending on what they consider is needed to achieve the highest grades.

\section{Tactics in relation to strategies}

A student's choice of tactics is guided by his or her own strategy and this choice determines the learning outcome, for example, whether learning is concerned chiefly with memorising or with comprehending.

As can be seen in the model, surface learners will show the greatest interest in memory directed tactics. Such tactics are concerned with storage and retrieval of information, for example, repetitive rehearsing of information and mnemonics. Deep learners will be more interested in comprehension-directed tactics; tactics (such as categorizing and productive thinking) that emphasize an understanding of the meaning of ideas and their interrelationships (see also Levin, 1982). They prefer tactics like transforming information. The 'deep student' will furthermore appreciate examples and an opportunity to translate information into his or her own words (Schmeck, 1988b).

\section{Learning styles and the Electronic Study Book}

In what way can we implement learning strategies and thereby learning styles in an electronic study book environment? We will look at different aspects of this question in the following paragraphs.

\section{Perceptions in relation to electronic study books}

In the environment of an electronic study book teacher actions can be minimized. In the first place, many of the tasks of the teacher can be automated. Second, the electronic study book offers ample opportunities for 
the learner to control the learning process, thereby increasing self-efficacy and a feeling of responsibility. Third, the electronic study book could offer as much help as a learner needs to understand the information, as an electronic study book can be made highly adaptive to the actions of learners.

These three aspects could have a positive influence on learners' perceptions (Ramsden, 1984). Learners become more interested, invest more energy in understanding the meaning of the information, use more selfreflection, and become more self-confident. This means in general that by offering learner control, by adapting to actions of learners, and by providing ample help-functions, the intentions and motives of a learner can change positively during the learning process.

\section{Electronic Study Books, learning strategies and learning styles}

If an electronic study book is to be able to adapt to a learner's preferred strategy, it must be able to offer information in several ways. For example: more repetition of main concepts or ideas has to be offered to support a rote learning strategy.

Three kinds of features have to be available to support a comprehension learning strategy. First, features to support the presentation of prerequisites, of relations between the prerequisites, and of relations between prerequisites and the information that is to be learned. Secondly, features have to be available that allow additional contextual information. Finally, 'imagery features' (such as graphics, animations, video) are to be available on demand.

Three ways of presenting information are needed to support an operation learning strategy. First an overview of the main ideas and the relations between must be available. Second, it must be possible for a learner to relate certain ideas to other ideas that are not part of the current subject matter. Finally, it should be possible to present supporting evidence for statements made about main ideas in an explicit way. Thus, a learner is allowed to examine evidence for flaws.

If we consider the learner to be the one who controls the processing of information contained in the electronic study book, we may assume that the learner will try to impose his own preferred learning style. The electronic study book then, should offer a learner options to harmonise the book to his or her preferred style of processing.

\section{Operationalizing learner characteristics}

It is of limited value to try to assess a learner's style completely. Rather we would like to attempt to assess operational characteristics that make up a specific style. Such characteristics could be transformed into software switches which the learner sets to select a particular learning style. 


\section{A Style Initiating Module (SIM)}

A Style Initiating Module is used at the beginning of the learning process. It is used to assess the initial learning style of a learner entering the electronic study book environment.

The SIM must not be perceived by learners as a part of the learning material and we do not consider the SIM to be so voluminous that it will take more than two minutes to complete; it should be as short as possible.

The Style Initiating Module consists of a number of neutrally stated multiple choice questions. The answers to these questions result in a Learner Specific Score (LESS) which defines an initial style. The SIM contains questions concerning motives, personal intentions in school-based learning (attitude), and the preferred strategy for processing information. Such questions can be derived from the various approaches to learning that are distinguished by Entwistle. The answers to the questions contained in the SIM determine directly the setting of the switches. Every question relates to a specific switch.

In regard to learners' motivation there are two switches that successively relate to fear of failure (if a learner is afraid that he or she will fail an exam, the switch will indicate a preference for a surface style, otherwise the switch will indicate preference for a strategic style), and competition sensitiveness (as representing a strategic style). The latter switch depends upon the learners either matching their efforts to the performance to be assessed (indicating a strategic approach to learning) or not (indicating either a surface or deep approach to learning).

There is one switch relating to learners' intentions. It distinguishes between learners who follow a course because they want to achieve personal understanding (which would indicate a deep style) and learners who want to be successful (indicating a strategic approach).

Two switches relate to strategy. The first switch distinguishes between exploratory learners and learners who use memorising strategies. The second switch concerns how a learner remembers new information.

What questions should be part of the SIM?

The Learning And Study Strategies Inventory (LASSI) as presented by Weinstein et al. (1983), contains questions relating to motivations, intentions, and strategies. In combination with information extracted from Entwistle's model we have constructed the first five questions. The last question is used to assess the initial domain knowledge of the learner.

Every question corresponds to one switch. The LESS is comprised of the combination of these switches. In Table 2 a matrix is constructed in which learning styles are combined with the six switches which are represented by Roman numerals. The corresponding questions can be found in the Appendix.

As can be seen in the matrix, the last switch has no specific value. This is because it depends upon the number of basic concepts a learner is not familiar with. 
122 I.P.F. De Diana and G. van der Heiden

Table 2. The style-switch matrix.

\begin{tabular}{lllllll}
\hline & I & II & III & IV & V & VI \\
\hline deep & 2 & 1 & 2 & 2 & 2 & $1 / 2$ \\
strategic & 2 & 2 & 1 & 2 & 2 & $1 / 2$ \\
surface & 1 & 1 & 2 & $1 / 2$ & $1 / 2$ & $1 / 2$ \\
\hline
\end{tabular}

SIM in relation to $E S B$

Using the results of the SIM, an electronic study book could form a basic learning environment. This could be done if the environment has an instructional theory available. Instructional theories regarding computerized instruction are known as second generation instructional design (ID2) (Jones, $\mathrm{Li}$, \& Merrill (1990)). Here, we presume the use of Merrill's analytic Component Design Theory (CDT) (Merrill, 1987). Merrill translates learning tasks into specifically coded primary parts that are to be taught in sequences. The division and coding of knowledge into primary parts helps to prepare electronic study book materials for instruction. The output of the SIM can determine the way in which the study book materials are to be preferably sequenced (for example first the explanation of a concept, then the presentation of an instance and finally asking for an instance).

\section{Conclusions}

The concept of learning style has been discussed and related to various learning strategies. It has been claimed that an electronic study book is able to offer options in the way it presents information to meet the individual needs of learners, in accordance with their preferred strategy and based upon adequate learning tactics. An instrument has been introduced to measure aspects of learning style, the results of which could be used by a style initiating module of an electronic study book. Style initiation could be performed by setting 'style' switches.

It is the conviction of the authors that additional research is needed in order to develop more detailed options for relating style of learners with design options for electronic (study) books. Based upon the results of such research, electronic (study) book platforms could be equipped with practical tools for adapting books to the needs of individual learners. 


\section{Appendix}

Questions/Switches of the SIM

\section{When I start a course:}

1. I try to make clear the grounds upon which my teacher will decide if I am good or bad in the subject.

2. I do not think of what exactly ought to be learned.

II. What is your goal when starting a course?

1. I want to understand what it is about.

2. I just want to finish it.

III. How do you feel when having an exam?

1. Worrying about doing poorly interferes with my concentration on tests.

2. When I begin an exam, I'm pretty confident that I will do well.

\section{How do you tackle learning?}

1. I try to find relationships between what I have to learn and what I already know.

2. I try to memorize what is being said or written down.

V. How do you remember things?

1. When having difficulty recalling something, I make an effort to recall something else that might be related to it.

2. I think of abbreviations for important concepts.

VI. Which concepts are not familiar to you? 
124 I.P.F. De Diana and G. van der Heiden

\section{References}

Bandura, A. (1982) Self-efficacy mechanism in human agency. American Psychologist, 33, 344-358.

Barker, P. (1990) Authoring electronic books. Computer Education, November, 2-5.

Barker, P. (1991) Editorial: special issue on Electronic Books. Educational \& Training Technology International, 28, 4, 269-271.

Barker, P. \& Manji, K. (1989) Designing electronic books. Joumal of Artificial Intelligence in Education, 1, 2, 31-42.

Biggs, J. (1988) Approaches to learning and to essay writing. In Learning Strategies and Learning Styles (ed. R. Schmeck) pp. 185-228. Plenum Press, New York.

Borenstein, N. \& Thyberg, C. (1991) Power, ease of use and cooperative work in a practical multimedia message system. International Journal of Man-Machine Studies, 34, 229-259.

De Diana, I.P.F. (1991) Electronic study book platforms. Educational and Training Technology International, 28, 4, 347-355.

De Diana, I.P.F. \& de Vries, S. (1990) Adaptable educational courseware. Journal of Research on Computing in Education, 23, 2, 225-242.

Egan, D., Remde, J., Landauer, T., Lochbaum, C. \& Gomez, L. (1989) Acquiring information in books and superBooks. Machine-Mediated Learning, 3, 259-277.

Entwistle, N.J. (1988) Motivational factors in students' approaches to learning. In Learning strategies and learning styles (ed. R.R. Schmeck) pp. 21-51. Plenum Press, NY.

Johnson, D.W. \& Johnson, R.T. (1987) Learning together and alone: cooperative, competitive and individualistic learming. Prentice-Hall, Englewood Cliffs, NJ.

Jones, M.K., Li, Z. \& Merrill, M.D. (1990) Domain knowledge representation for instructional analysis. Educational Technology, 10, 7-32.

Lai, K., Malone, T. \& Yu, K. (1989) Object Lens: A 'spreadsheet' for cooperative work. ACM Transactions on Office Information Systems, 6, 332-353.

Levin, J.R. (1982) Pictures as prose-learning devices. In Advances in Psychology, Vol. 8: Discourse Processing (eds. A. Flammer \& W. Kintsch) North-Holland, Amsterdam.

Marton, F. \& Saljö, R. (1984) Approaches to learning. In The Experience of Learning (eds. F. Marton, D. Hounsell \& N. Entwistle) pp. 36-55. Scottish Academic Press, Edinburgh.

Merrill, M.D. (1987) The new component design theory: instructional design for courseware authoring. Instructional Science, 16, 19-34.

Moulin, B. \& Rousseau, D. (1990) Designing deontic knowledge bases from regulation texts. Knowledge-Based Systems, 3, 2, 108-120.

Paris, S.G. (1988) Learning Strategies. In Learming and Study Strategies: Issues in Assessment, Instruction, and Evaluation (eds.. C.E. Weinstein, E.T. Goetz \& P.A. Alexander) pp. 299-321. Academic Press, San Diego.

Ramsden, P. (1984) The context of learning. In The Experience of Learning (eds. F. Marton, D. Hounsell \& N. Entwistle) pp. 144-164. Scottish Academic Press, Edinburgh.

Schmeck, R.R. (1988a) An integration of perspectives. In Learning Strategies and Learning Styles (ed. R.R. Schmeck) pp. 317-347. Plenum Press, New York.

Schmeck, R.R. (1988b) Individual differences and learning strategies. In Learning and Study Strategies: Issues in Assessment, Instruction, and Evaluation (eds. C.E. Weinstein, E.T. Goetz \& P.A. Alexander) pp. 171-191. Academic Press, San Diego.

Weinstein, C.E., Schulte, A.C. \& Cascallar, E.C. (1983) The Learning And Study Strategies Inventory (LASSI): Initial design and development (Final Report). Army Research Institute for the Behavioural and Social Sciences, Alexandria, VA. 